\title{
Research on the Quality of College English Teaching Design Based on BOPPPS Model
}

\author{
Yin Hongtao \\ College English Department Zaozhuang University \\ Zaozhuang, Shandong Province, China
}

\begin{abstract}
Most researches focus on the exploration of teaching mode and ways to improve the quality of college English teaching. In addition, the paper emphasizes the importance of the monitoring system for the quality of English teaching. The BOPPPS teaching model is an advanced educational concept and the basic elements of the BOPPPS model are used to design framework. The corresponding teaching models are designed in combination with the characteristics of the college English classroom. Based on the six elements of BOPPPS model, the basic characteristics of teaching design and the core principles of college English classroom, this paper designs a college English classroom teaching model with BOPPPS model and tries to provide an application model for teaching design. The research data shows that this role reversal can help students master more than $90 \%$ of knowledge taught in class, thus achieving the effectiveness of classroom teaching.
\end{abstract}

Keywords-College English class teaching; Teaching quality; BOPPPS theory; Monitoring system

\section{INTRODUCTION}

After the rapid development of higher education, the improvement of educational quality has attracted the attention of the whole society. College English, as the most extensive public foundation course, has been highly valued by the Ministry of Education. In April 2003, the Ministry of Education officially launched the "Quality and Teaching Reform Project in Colleges and Universities". Since then, the State has listed the reform of college English teaching as the second of the four tasks of "Quality Project".

In the document "Several Opinions on Further Deepening Undergraduate Teaching Reform and Comprehensively Improving Teaching Quality", the Ministry of Education clearly requests to further promote and implement the reform of college English teaching, to comprehensively promote the fruits of college English teaching reform, and to make full use of high-quality teaching software and teaching resources to deepen the college English teaching. The document also states that the reform of English teaching content and teaching methods should promote the establishment of a new mode of English teaching in the network environment, and effectively promote the comprehensive application of English for college students, especially the improvement of listening and speaking ability [8]. The requirements of the Ministry of Education have driven the upsurge of college English teaching reform. At the same time, many schools have focused their research on

The thesis is a phrasal achievement of "Research on the Quality of College English Teaching Design Based on BOPPPS Model” in Zaozhuang University, A teaching reform project in 2017. college English teaching methods, teaching content and teaching methods.

The quality of education is a complex and vague concept. Establishing a monitoring system for teaching quality helps to ensure the quality of teaching and improve the level of education. The quality of teaching in classroom is the core content of education quality. The monitoring system for teaching is a process of management with various measures and actions adopted to achieve certain quality standards. To achieve this goal, various factors affecting teaching quality in the teaching process are systematically supervised and controlled to ensure the continuous improvement of teaching quality.

With the popularization of higher education, the quality of students, the level of teachers, the teaching equipment and the management level, especially the change of teaching concepts are all facing unprecedented challenges. English classroom teaching is no longer a cramming teaching supplemented by teachers in traditional ways. It is an autonomous learning aiming at achieving improved language skills through learning. At present, monitoring system for the quality of English classroom teaching is relatively rare. The research on the quality monitoring and guarantee system of college English teaching is not deep and perfect enough. Most of the researches are focused on the exploration of teaching mode and the ways to improve the quality of college English teaching. The research on the monitoring system for quality of college English teaching needs to be strengthened.

\section{THE INTRODUCTION OF BOPPS MODEL}

Originally created in 1976 by the team of Douglas Kerr in University of Vancouver, the BOPPPS model is an effective curriculum design model proposed by the Instructional Skills Workshop (ISW) of North American colleges and universities. The main feature of the BOPPPS model is to emphasize the participatory learning approach, with clear teaching objectives and targets. The BOPPPS teaching model modularizes the teaching process and divides the course into six stages according to the transition, namely, Bridge-In, Objectives, Pretest, Participatory Learning, Post-test and Summary.[6] It provides teachers with a complete framework and theoretical support covering all aspects of classroom teaching.[5] The teaching mode is practical and operable, which makes the arrangement of classroom teaching more organized and rationalized, and it provides clear logic and effective 
guarantees for the achievement of classroom teaching objectives. It has become the standard for higher education teacher training and classroom teaching in Canada [3].

The BOPPPS teaching model is an advanced educational concept. Its effective implementation can help students improve their interest in learning English, and make students truly become the main part of the classroom, exerting subjective initiative and enhancing the effect of their own learning [1]. At present, China has begun to introduce the B0PPPS teaching model in practical teaching, but more is the experience summary combined with the actual curriculum. Most of the research is focused on the exploration of teaching mode and the ways to improve the quality of college English teaching. The research on the monitoring system for quality of English teaching needs to be strengthened.

\section{Common Problems of Traditional Classroom TEACHING}

The teaching of knowledge points is mainly on the systematic nature of knowledge, the definition of basic concepts, the structure of knowledge and the application of knowledge. However, traditional university classroom teaching is often implemented by teachers to teach these concepts and knowledge, and students are just listeners. The current classroom teaching activities mainly have the following problems [2].

(1) There is no clear teaching goal, just to list the knowledge, so that students do not know the aim of learning this knowledge.

(2) The teachers pay excessive attention to the systematic nature of knowledge. In the limited class time, regardless of key knowledge or peripheral knowledge, teachers explain large number of language points through of PPT screenings, and students are often indigestible and most of the content is forgotten before the exam.

(3) Teachers do not have a deep understanding of the teaching content and knowledge system, and lack personal experience of knowledge, resulting in a lack of grasp of teaching priorities.

(4) The students are the audience. The students take very little or even no participation. Because of the electronic courseware, the students do not even take notes, let alone the classroom practice, which makes the students easy be absentminded in class.

(5) Lack of feedback information obtained from students in a timely manner makes the teaching effect greatly reduced.

(6) There are little explanations on the relations among introduction of knowledge points, technology realization and technological evolution, which is the result of teachers' limited understanding of knowledge points and teaching skills [11].

\section{CHARACTERISTICS ANALYSIS OF BOPPPS TEACHING MODEL}

In 1984, David Kolb proposed an experiential learning model. Cooper believes that learning is not the acquisition and transmission of content, but the process of creating knowledge through the transformation of experience. He interprets learning as a cyclical process with specific experiences as the starting point and ending point, that is, specific experiencereflexive observation - abstract generalization- action practice- specific experience. A coherent learning experience is formed through continuous circulation, and in the learning process, the feedback and adjustments are automatically completed by the learners. The BOPPPS teaching model is a teaching framework based on the Kolb experiential learning model. The BOPPPS model divides the classroom teaching process planning into six phases (or elements): Bridge-in, Objective, pre-assessment, Participatory Learning, Post assessment, Summary.

Bridge-in is often referred to as a "hook", which causes the students' curiosity to generate learning motivation to introduce new content. The objective element which is mainly based on the three aspects (recognition, emotion and skill) of the Bloom learning target classification, clearly points out the requirements and levels that should be achieved through learning. The pre-assessment is mainly used to evaluate what learners know and understand now, to guide the follow-up of teaching, and to remind the learners of the knowledge has learned. The participatory phase is mainly the process of using the active learning strategy to enable the learner to deeply participate in the classroom to achieve the teaching goal. The post-assessment is mainly to make clear of the degree of mastery of knowledge associated with the teaching goal after the class learning. The summary is mainly to provide teachers and learners with a common opportunity for reflection, during this stage students reflect on what they have learned and teachers reflect on the problems of this class or lay an ambush for the next course content [7].

\section{PROCESS ANALYSIS OF BOPPPS MODEL OPERATION}

Generally speaking, according to the occurrence time of teaching activities, it is divided into three stages: extracurricular stage (including pre-class and after-class), inclass and after-class [12]. Here, the basic elements of the BOPPPS model are used to design framework, and the corresponding teaching models are designed in combination with the characteristics of the college English classroom.

\section{A. Pre-class Stage}

When designing a course, the first task is to clarify the teaching objectives. The goal can be formulated under the theory of Bloom classification to express the cognitive level of teaching and to design the class in accordance with the principles of the Recent Development Zone.

On the basis of clarifying the teaching objectives of the course, the teacher has targeted the content of the pre-test to understand the student's learning level and the knowledge reserved. Different from the traditional prevision, the pre-class study puts higher demands on the level of knowledge transfer, 
even more than the effect of traditional classroom lectures. This goal undoubtedly puts higher demands on teachers' task design before class [4].

On the one hand, teachers should consider how to design the learning tasks that can be achieved according to the students' ability level; on the other hand, teachers design measurable standards to know the students' learning state. In the students' self-learning, teachers also need to provide certain assistance and guidance, including micro-videos that provide knowledge points and well-designed learning materials, such as "Basic Academic Survey Form" and "Pre-class Learning Guidance Form", etc. [9] As to the questions and puzzles they meet, Students will receive feedback and support in a timely manner during the learning process.

In addition, before entering the in-class stage, students should be tested before class to examine the students' knowledge of the pre-class stage and lay the foundation for follow-up learning.

\section{B. In-Class Stage}

In this stage, how to design an effective Bridge-in is first considered. Effective introduction ensures that students and learning content are linked in some ways. This association can increase students' commitment and attention in pre-class learning and help students complete their learning tasks more efficiently. In the classroom, the introduced design can appear in many forms, such as games, questions, setting conflicts, etc. In the introduction, teachers can set the context related to the teaching content, find some associations between the text and students' existing experience, or ask a question to arouse the interest of students.

The teacher will design tasks in advance based on the knowledge points involved in the teaching objectives and the problems generated by the students in the early stage. The design of the task should be considered from the following aspects:

a. The design of the task can reflect the requirements in the teaching objectives and reflect the inspection of the knowledge points.

b. The task description is specific other than described in general terms.

c. The design of the task can attract students' attention.

d. The design of the task is hierarchical, considering students with different learning levels, and extension issues should be designed for students to choose.

e. Provide the necessary supporting resources to complete the task.

Teachers organize students to carry out participatory learning activities around pre-designed learning tasks and explore new knowledge while deepening knowledge has been learned. In group discussions, each group discusses around a topic. At this time, teachers need to grasp the direction, pay attention to the learning dynamics of each group, and provide targeted and personalized guidance on various problems that may arise. Throughout the process, teachers and students maintain active and effective interactions. And through communication and feedback, they guide students to cooperate to build and improve their knowledge systems.

After the cooperation and exploration in the group, each group separately sorts out and summarizes the harvests in the discussion in some ways, and exchanges the problems encountered, the solutions and ideas with other groups to share the harvest. After the report and communication, the teachers concentrate on the difficult problems of each group, sum up the teaching objectives and help the students to further consolidate the knowledge and form a holistic understanding of the course content. In the process, students and teachers can reflect with tools that record feedback.

\section{After-class Stage}

Teachers can arrange the timing of post-testing according to the specific situation, either in the after-class stage or after the teaching activities in the class. Through post-testing, it helps to understand the development of students after class, and tests students' learning effects through various forms, such as questions, tests, and competitions. The content of the test should reflect the student's mastery of the teaching objectives, consider how students use knowledge to solve practical problems or allow students to create an executable plan. In addition, in the after-class stage, teachers can also provide more abundant learning resources for students to further extend their studies [10].

\section{ANALYSIS OF TEACHING STRATEGIES OF BOPPPS MODEL}

Different from the traditional classroom teaching mode, the classroom teaching based on BOPPPS model introduces new teaching methods that enhance efficiency and technical strategies. The different teaching efficiency strategies used in classroom teaching will result in different combinations of teaching methods, classroom structure and operational processes. The teaching effectiveness-enhancing strategy adopted by the BOPPPS model is a group-cooperative learning strategy. In the process of mutual learning during teacherstudent interaction and students' interaction themselves, the learner's information acquisition channels are diversified, and conditional support of the "Student Teacher Role" is provided for students' self-learning and personalized learning. In the interactive process of playing the role of "teacher", students can not only expand the depth of learning, but also achieve counseling for groupmates. The research data shows that this role reversal can help students master more than $90 \%$ of knowledge taught in class, thus achieving the effectiveness of classroom teaching. 


\section{CONCLUSION}

Based on the six elements of BOPPPS model and the basic characteristics of teaching design and the core principles of college English classroom, this paper designs a college English classroom teaching model with BOPPPS model and tries to provide an application model for teaching design. In the process of implementing the flipped classroom, the teacher can follow the basic principles of the college English classroom, select appropriate teaching strategies according to the teaching content and academic analysis, and design a feasible teaching plan.

The classroom design based on BOPPPS model requires teachers and students to do a lot of preparation work before and after class. Students need to memorize the simple level of knowledge before or after class, while the deep application and analysis process needs to be completed under teachers' guidance in class. In the teaching practice, it is forbidden to make the classroom organization activities become a mere formality. On the surface, the students are involved in the activities, but it is only superficial. The true deep participation in the classroom should be involved with heart and mind.

The six components of the BOPPPS model can also be used according to the specific teaching objectives and flexible content of the teaching content. The classroom teaching activities cannot be rigidly organized, so that the classroom teaching design will not be limited to a fixed frame or model or falls into the misunderstanding of the formalization of teaching organization.

\section{REFERENCES}

[1] Chen, G.M. \& Starosta, W.J. Intercultural communication competence: A synthesis [J]. Communication Yearbook,1996 (19) 353-383.

[2] Robinson Peter. Cognition and Second Language Instruction. Cambridge: Cambridge University Press, 2001.

[3] Pattison P, Russell D. Instructional Skills Workshop Handbook [M]. Vancouver: UBC Centre for Teaching and Academic Growth, 2006.

[4] Allan J. Learning outcomes in higher education [J]. Studies in Higher Education, 1996 (1): 93-108.

[5] Wu Jihong. The quality monitoring system of college English classroom teaching based on SIOP and BOPPPS mode. Journal of Yibin University [J]. Journal of Yibin University, 2015 (5): 122-125.

[6] Chen Weiwei, Bao Aihua, Li Qing. Teaching Design of Cultivating Computational Thinking Based on B0PPPS Model and Problem-Driven Teaching Method [J]. Industrial and Informatization Education,2014(6): 8-11.

[7] Yuan En, Liu Peng, Qi Wangdong, et al. Teaching Reform of Computer Network Principle Based on BOPPPS Mode[J]. Computer Education, 2015 (3): 26-29.

[8] Ministry of Education. Teaching Requirements for College English Courses [C]. Beijing: Foreign Language Teaching and Research Press, 2007.

[9] Xiao Weicai. Exploration and Practice of Integrated Teaching Mode of Theoretical Teaching and Practical Teaching[J], Laboratory Research and Exploration, 2011, 30(4): 81-84

[10] Wang Jingwei, Review of American Inquiry Teaching Model. Shanghai Education Research [J], 2010 (4): 61-63

[11] Yang Aiying. Comparative Study and Enlightenment of Chinese and English Higher Education Teaching Models [J]. Heilongjiang Higher Education Research, 2006 (9): 17-19.

[12] Tan Chunjiao. Combining the Canadian model to carry out the training of teachers' teaching skills in China [J]. Computer Education. 2014(4): 47-50. 